\title{
THE ADEQUACY OF CAPITAL MARKETS FOR RURAL NONFARM BUSINESSES
}

\author{
Glenn Rogers, Ron Shaffer and Glen Pulver*
}

The recent farm crisis has increased awareness of nonfarm businesses' contribution to future economic development in rural areas. Rural area residents increasingly depend on employment off the farm. A crucial determinant of rural nonfarm businesses growth is the adequacy of local capital markets.

Two views currently exist concerning the functioning of rural capital markets. One view holds that capital is available for businesses to use but that there is a shortage of businesses and business ideas. The second view holds that business ideas exist but capital markets are inadequate and this lack of funds restricts rural economic development. This paper presents an empirical test of the second view. Capital markets are judged as adequate when after adjusting for risk, all firms, regardless of their local capital market, have equal access to debt and equity financing. Equal access does not imply equal cost: the issue is availability, not cost of funds. Statistical rejection of the null hypothesis implies that capital gaps exist and that inadequate financing restrains rural nonfarm businesses.

Previous research reached mixed conclusions regarding capital market adequacy. Research that uses primarily supply side data concludes that only minor, if any, financing gaps result from inadequate market performance (Horvitz and Pettit, 1984). Research that uses demand side data (Garvin, 1971) or directly combines supply and demand side data in a risk adjusted framework, suggests that financing difficulty is a constraint for a significant number of lower risk borrowers (CNEA, 1981; George and Landry, 1959).

Theoretically, financial markets perform adequately when all users have the same access to financial capital after adjusting for firm specific risk. The financial market is inadequate if businesses have difficulty obtaining funds because of reasons that reflect excessive information or transaction costs, or institutional limitations (Mikesell and

\footnotetext{
*Research Associate and Professors of Agricultural Economics, University of Wisconsin-Madison. The results reported are from a study funded by the Economic Development Administration Technical Assistance Project \#99-7-13654, the Agriculture and Rural Economy Dividions of the Economic Research Service of the U.S. Department of Agriculture Memorandum of Understanding 58-3195-5-00397 and the College of Agriculture and Life Sciences, University of Wisconsin-Madison.
}

Davidson, 1982). Establishing a precise measure of the nature and extent of capital inadequacy is difficult.

If existing businesses can easily obtain funds, capital markets, by definition, are functioning adequately for them. The fact that businesses have difficulty obtaining financing is a necessary, but not sufficient condition for a financial market adequacy problem. It cannot be concluded that there is a market problem if a business has difficulty obtaining financing because it is a risky business or a poor investment. One of the functions of the financial market is to discriminate between good and poor investment options. Riskier businesses should have restricted access to finance in a properly functioning market.

Risk is difficult to assess. Capital market transactions are a complex combination of firm-specific characteristics and lender size, portfolio considerations and other factors. For example, a low risk firm may seek a loan which it can easily repay, but may have its proposal rejected because the request is above the lender's limits or further concentrates the lender's loan portfolio. When attempting to measure capital adequacy caution must be exercised when accounting for risk. Risk adjustment is less a problem when relating general business and lender characteristics than when assessing specific loans.

Capital adequacy is difficult to measure for other reasons as well. Business surveys provide little information regarding firms which are unable to get started or which have failed because of the lack of capital. Furthermore, a test of difficulty in acquiring capital within a specific industrial sector or region provides no assessment of the relative profitability of an investment in one sector or region versus in others.

This study recognizes it is impossible to precisely measure capital market adequacy for rural nonfarm businesses. Instead the work measures the relative difficulty in acquiring capital for firms of varying types after attempting to account for major risk indicators. In this study, a capital market is considered inadequate if businesses have difficulty obtaining funds because of non-risk reasons.

\section{General Model for Identifying Market Inadequacies}

This paper models the availability of finance as a linear function of independent variables representing busi- 
ness-specific risk factors and non-risk related characteristics of businesses and local lenders. An econometric model of business finance availability is fully specified when all dimensions of business specific risk have been included. Non-risk factors are also included to identify sources of market inadequacies.

The model to be estimated is

ADEQUACY $=\mathbf{f}$ (Firm Characteristics, Lender Market Characteristics; Firm Risk Specific Characteristics)

where

ADEQUACY isamulti-dimensional measure of market adequacy

Firm Characteristics are nonrisk dimensions of a firm, including size, ownership form, nonlocal locations, and use of various maturity loans;

Lender Market Characteristics measure local capital supply conditions like lender market concentration, lender experience, and lender efforts to expand markets;

Firm Risk Characteristics measure a firm's risk status, including sales growth, business development stage, debt load, management experience and sector.

No single measure of availability of finance could be used as a dependent variable. In this paper, market adequacy is measured by five different dependent variables based on businesses capital market experiences: 1) denial of a loan request; 2) underfunding of a financing request; 3 ) the proportion of new debt obtained from a commercial bank; 4) the proportion of new debt obtained locally, and 5) the proportion of new equity obtained locally.

The first two dependent variables are coded as " 1 " if businesses experienced financing difficulty and " 0 " otherwise. When the dependent variable represents a percentage response, the actual percentage is used.

Two statistical methods are required since two types of limited dependent variables are used ( 0 or 1 and 0 to 1 ). Probit is used for the 0 or 1 dependent variables. Logit is used for the 0 to 1 continuous dependent variables. See Shaffer, Pulver, Rogers, Wojan and Gerland (1989) for a fuller discussion.

The hypothesis of market inadequacy is rejected if the independent variables measuring non-risk forces have insignificant coefficients. In these multivariate equations risk is controlled for by introducing firm specific risk characteristics. Maximum likelihood estimation (MLE) techniques are used to improve the efficiency and consistency of the coefficient estimates given that the dependent variables are hypothesized to be a function of several dichotomous independent variables.
A derivative of the estimated equations measures the effect of that independent variable on the proportion of businesses in a local market having the dependent variable characteristic, or equivalently, the effect on the probability that an individual business will have the characteristic. With a binomial probability distribution, the probability that an individual firm will have a characteristic is the same as the proportion of the entire population with the characteristic. In some cases it is easier to interpret the derivative as an individual firm's change in probability (such as lender familiarity of an individual firm with respect to all other firms in its market). In other cases, it is easier to interpret the derivative as a change in the proportion of firms with the dependent variablecharacteristic, given a market-widechange which affects all firms (such as the concentration of nonfarm lending in the local market). The results section of this paper uses both interpretations because they are equivalent.

In the case of linear models, these derivatives are constant. However, MLE is a nonlinear technique which provides different estimates of the derivatives at different values of the independent variables. All derivatives presented in this analysis are evaluated at the mean of the respective independent variables. To understand the variation in the magnitude of the derivatives it is necessary to calculate the derivative at different levels of the independent variables.

The primary concern of this research is the significance and sign of individual coefficients in the multivariate equations and only secondarily the magnitude of the derivative with respect to a particular independent variable.

The analysis used primary data obtained through a survey of 2,046 businesses drawn in a random stratified sample from a population of 4,724 businesses in four Wisconsin rural counties. Usable responses to the December 1986 mail survey were received from 815 firms. In these same counties, chosen for their diverse economic characteristics, all 37 formal lenders (banks, savings and loans, and credit unions) were personally interviewed to obtain the supply side data used in the following analysis.

The unit of observation is the individual business firm, so lender characteristics become supply characteristics for each business located in that lender's market. Lenders and businesses were grouped into fifteen community bank markets for nonfarm business loans based on lender descriptions of the local geographic market boundaries (Rogers, Shaffer and Pulver, 1988). Characteristics of businesses and lenders are used as independent variables in the multivariate equations.

\section{Measures of Risks}

Five business firm characteristics are used in the multivariate analysis to indicate the risk dimension of the request. 
The risk impact of recent changes in sales is measured with three dummy variables relative to firms with a 1985-86 change in sales of $-5 \%$ to $+5 \%$ : businesses with sales growth rates faster than $5 \%$, slower than negative $5 \%$, and firms too new to report sales growth.

Repayment capacity is measured by two variables: debt relative to sales volume; and debt relative to assets. The first ratio provides a crude measure of the cash flow approach to repayment capacity, while the second indicates a collateral approach. Higher ratios reflect more risk and therefore more difficulty acquiring funds.

Businesses are grouped into four business sectors with 0-1 dummy variables to measure differences relative to the retail sector. There is no a priori expectation on the sign of these coefficients. For low risk sectors the expected coefficient is negative, and for higher risk sectors the coefficient's expected sign is positive.

Start-ups and ownership transition businesses, do not have a proven track record, and are riskier than businesses such as maintenance stage or expansion stage firms. Three dummy variables for stage of business development are used to measure differences relative to maintenance stage firms: 1) start-up stage, 2) expansion stage, and 3) ownership transition stage. The expected coefficient sign on all business stage dummies is positive.

Business manager experience is measured by number of years the owner or manager has been with the current firm. The expected sign on this coefficient is negative, indicating that more experienced managers are associated with less risky financing requests.

Significant coefficients with the proper sign on the risk variables do not indicate financial market inadequacy, but rather that the market is appropriately using these measures of risk to limit financing to risky firms. Insignificant coefficients on risk variables need not indicate market inadequacy, but merely that risk variation, as measured by that particular variable, is not an important source of financing difficulty. Insignificant coefficients may occur because of a lack of variation within the sample or because other risk factors are more constraining. In general, significant coefficients with improper signs on the risk variables do indicate market inadequacies: the market is discriminating against lower risk firms in allocating finance.

\section{Business Characteristics Indicating Inadequacy}

Four categories of business characteristics indicate market adequacy problems if they are significantly correlated with finance availability afteradjusting for firm specific risk: 1) access to nonlocal financing, 2) term structure of loans, 3) access to nonbank financing, and 4) sector familiarity. If the coefficients on any of these variables are significant, that indicates an adequacy problem.

\section{Access to Nonlocal Financing}

Businesses with limited access to nonlocal capital sources are particularly vulnerable to local decision criteria. Business characteristics which increase access to nonlocal finance are number of nonlocal locations and firm asset size. Businesses located in more than one community (at least 15 miles away) have greater flexibility in financing sources. Larger firms ( $\$ 100,000-499,999$ and $\geq \$ 500,000$ assets) are anticipated to have greater nonlocal access and are compared to smaller firms via two dummy variables.

\section{Term Structure of Loans}

Short-term debt is defined as a loan with a maturity of less than twelve months. Medium-term debt is a loan with a maturity of between one year and five years. Long-term debt has a maturity greater than five years. For example, use of short-term debt is measured by the number of short-term loans received during 1985 and 1986 . Financing availability is independent of the term or number of loans a firm uses.

\section{Access to Nonbank Financing}

Forms of business organization that represent involvement of multiple individuals in the firm suggest greater access to informal equity and debt financing. Access to nonbank financing is measured by dummy variables for three forms of business organization relative to sole proprietorships: 1) partnerships, 2) corporations, and 3) other organizational forms which are predominantly cooperatives.

\section{Sector Familiarity}

The relative familiarity about a particular sector (firm sector share) is measured as the proportion of all local firms in the same economic sector as the business. For example, retail businesses are represented by the share of retail firms in the local market as estimated by the sample of survey respondents. In an individual market all firms in the same economic sector have the same measure of familiarity. Firms in sectors that make up a larger share of the local economy should experience less difficulty in acquiring financing because lenders should be more knowledgeable than sectors with smaller shares.

\section{Lender Market Characteristics Indicating Inadequacy}

Relevant lender market characteristics include asset size, lending experience, concentration of lending in the local market, lending focus, and lending effort. In a market where businesses have access to several local lenders, the 
largest lender's characteristics are used. Larger local lenders generally have greater lending capacity than those which are smaller, all other things being equal. However, substantial research evidence indicates all other things are often not equal (Boggs et al., 1988; Sorenson \& Isserman, 1988; Taff et al., 1984). Since lender capacity is likely to vary with type of individual funding request, the simpler and consistent proxy of largest lender was used.

Lender asset size is an important determinant of lending capacity, such as lending limits. Lender capacity for an individual business is measured by the total assets of the largest lender physically located in the local market relative to the asset size of the business. A positive coefficient suggests smaller businesses experience more difficulty in markets with larger lenders, and a negative coefficient indicates less difficulty.

Lender experience with a specific business type is measured by the percentage of the lender's nonfarm business portfolio in that sector. For example, lender expertise in retail lending is measured by the percentage of the largest lender's nonfarm business loan volume in the retail sector. If this coefficient is significant and negative this indicates that increased lender expertise facilitates the availability of finance. If this variable is significant and positive financing may be limited by lender specialization or lender desire for portfolio diversification.

Concentration of lending in the local market is measured with a version of the Herfindahl-Hirschman Index of Concentration. The index used for this study is calculated by squaring each lender's 1986 percentage share of total local nonfarm business loan volume outstanding and summing the resulting set of squared shares. More concentrated markets have higher index scores. If this variable's coefficient is negative, lenders in concentrated markets are able to extract higher returns from prosperous local economies and are lending more aggressively (Barkley \& Helander, 1985; Ho, 1979). If positive, market concentration leads to local financing difficulty.

The lending focus of local lenders is measured by the proportion of local lenders claiming real estate lending as their major local investment activity. If this coefficient is significant and positive this indicates that nonfarm businesses in markets dominated by real estate lenders have more difficulty, and if negative, they experience less financing difficulty. Two possible reasons exist for a negative coefficient: 1) the constraint of long-term loans or collateralized loans for small business is relaxed with the expertise of real estate lenders, or 2) in markets dominated by real estate lenders, lenders are more likely to internalize a community prosperity lending focus (Barkley \& Helander, 1985).

Lending effort is measured with an index using six components of lending effort as reported by interviewed lenders.
The index of lending effort takes on the following values:

$=0$ if lender has adequate local demand,

$=1$ if demand is inadequate and the lender made efforts to expand financing to existing local businesses,

$=2$ if demand is inadequate and the lender also made efforts to help local business starts,

$=3$ if demand is inadequate and the lender also made efforts to bring new businesses to the local market,

$=4$ if demand is inadequate and the lender also made efforts to geographically expand the local market.

Financing difficulties should decline if lendersactively expand their nonfarm business lending.

\section{Multivariate Model Results of Market Adequacy}

Identifying a financing availability gap for rural businesses is difficult due to the multi-dimensional nature of the term adequacy. To overcome this problem, the analysis of financing gaps is based on two sets of proxies of local market inadequacy. First is the businesses' statement that they had a loan request denied or underfunded in the last two years. Second is the extent local capital sources were used to fund new (last two years) financing for the business. A Probit statistical model was used to create the estimated parameters for the first two indicators and a Tobit statistical model was used for the second set of indicators.

\section{Denial or Underfunding of Financing Requests}

This study considers two types of denial: denial of a loan which wasnot funded later, and underfunding of requests. If a business reported having at least one loan denied and never funded or underfunded these two variables were coded as " 1 ". Otherwise they were coded "0". Eighteen percent of the sample firms experienced denial of a financing request during the study period, however, only $13 \%$ reported that they had requests denied and never funded. Eight percent of the firms had a financing request underfunded.

Denial

After adjusting for business specific risk, both non-risk related business and lender market characteristicsare significant determinants of financing denial. As shown in column one of Table One, firms with over $\$ 500,000$ in assets are $10 \%$ more likely to have been denied finance than are firms with less than $\$ 100,000$ in assets. Firms with assets between $\$ 100,000-499,000$ are also more likely than the smallest size class to experience a denial. Sole proprietorships are more likely to be denied financing than are corporations or partnerships. Firms are also more likely to be denied financing in an economic sector in which the largest local 
lender already has a large proportion of loans. The positive coefficient on largest lender assets/firm assets indicates the smaller the firm relative to the size of the lender the more likely the firm is to experience a loan denial. The positive coefficient on lender experience implying more difficulty with a more experienced lender seems incongruous. The more experienced lenders, however, may be more selective in their lending practices, and this selectivity may increase the prospect of loan denial.

An individual business's risk characteristics are also important determinants of credit denial experience. Firms with declining sales, high debt to sales levels, or limited managerial experience were more likely to experience financing request denials (see column one of Table One). These signs are expected and do not indicate market inadequacy.

Individual business development stage coefficients are significant, but that class of dummy variables is not, suggesting no real influence on the likelihood of denial.

\section{Underfunding}

Firm characteristics correlated with underfunding of requests differ from the characteristics of firms denied finance, as shown in column two of Table One. While corporations are less likely to have requests underfunded and larger firms (over $\$ 500,000$ assets) are more frequently underfunded, those classes of dummy variables are not significant. Firms using medium- and long-term debt are also more likely to be underfunded. The positive coefficient on medium- and long-term loans could mean that some businesses encounter lenders reluctant to commit themselves to longer term loans and thus the lenders are inclined to underfund loans. None of the hypothesized lender market characteristics alter the underfunding experience.

The risk indicators of denial and underfunding also differ. Start-ups and expansion stage firms are underfunded more frequently than maintenance stage firms, while ownership transition stage firms are not. Start-up stage firms are $7 \%$ more likely to have requests underfunded than are maintenance stage firms, but are not more likely to be completely denied financing altogether. This suggests financial market inadequacy for start-up firms, seeking financing for expansion rather than the actual initiation of a new business. If start-up firms are riskier they would also be denied credit more frequently in addition to having requests underfunded. An alternative interpretation of this result is that those start-ups denied financing were not surveyed because they had closed or were unable to open their business.

As shown in column one of Table One, ownership transition stage firms are $6 \%$ more likely to be denied financing than maintenance stage firms. However, these firms are not more likely to have experienced underfunded financing requests. It is unclear whether this underfunding indicates that all ownership transition stage firms are categorically denied financing regardless of risk characteristics or whether these firms are actually riskier enterprises. It may represent the inclusion of non-risk aspects in the business development stage variable.

\section{Sources of New Financing Used}

Patterns of financial market use are not sufficient evidence to prove that capital market inadequacy problems exist. However, as supporting evidence to financing difficulty, market use pattems help identify types of market adequacy problems. The market use patterns examined include: 1) the proportion of new debt obtained from a commercial bank, 2) the proportion of new debt obtained locally, and 3) the proportion of new equity obtained locally. These three indicators are selected because of the importance of banks and local sources to business finance. The proportion of business financing obtained from these sources varies systematically across markets and types of businesses.

Market use is first measured by the share of new debt obtained from a bank. Sometimes, businesses of certain types and sizes acquire a low share of new debt from banks when compared to other businesses. This indicates that banks are not adequately meeting the financing needs of those businesses in their region. The second and third measures of market use are the proportion of debt and equity obtained locally. Since businesses obtain the major share of their new debt and equity locally (Shaffer \& Pulver, 1985), a small share of new financing from local sources indicates these sources are not adequately meeting the financing needs of selected local businesses. Obviously businesses can seek nonlocal sources, but empirical evidence indicates that most firms in rural areas do not do so.

\section{Share of New Debt Obtained from a Commercial Bank}

As shown in column one of Table Two, corporations and businesses using numerous short-term loans obtain the highest share of their new debt from a commercial bank. Corporations obtained $46 \%$ more of their new debt from a bank than did sole proprietorships. This evidence suggests that commercial banks are more actively involved in financing incorporated firms or those using short-term loans. This is not surprising, given the structure of bank deposits and the prospects that sole proprietorships may use more informal capital sources (friends, suppliers). This suggests that sole proprietorships and firms using medium- and 
Table 1

Business Experience of Denial and Underfunding of Financing Request

\begin{tabular}{|c|c|c|}
\hline & Denied & Underfunded \\
\hline Number of Observations ${ }^{2}$ & 418 & 513 \\
\hline Mean of Dependent Variable & 0.13 & 0.08 \\
\hline$\%$ of Responses Predicted Correctly & 87.83 & 92.41 \\
\hline \multirow[t]{3}{*}{ Log Likelihood Ratio Chi-Square for Equation } & $9.51^{* * *}$ & $45.72^{* *}$ \\
\hline & Partial & Partial \\
\hline & Derivative & Derivative \\
\hline \multicolumn{3}{|l|}{ Non-Risk Business Characteristics } \\
\hline Business Size Dummy Variables & *** & @ \\
\hline Assets $\$ 100,000-499,000$ & $0.0421 *$ & 0.0091 \\
\hline Assets $\geq=\$ 500,000$ & $0.1015^{* * *}$ & $0.0514^{*}$ \\
\hline Number of Nonlocal Locations & -0.0141 & -0.0019 \\
\hline Business Organization Dummy Variables & $* * *$ & @ \\
\hline Partnership & $-0.1113^{* *}$ & -0.0089 \\
\hline Corporation & -0.0407 & $-0.0326^{*}$ \\
\hline Cooperative & -0.7840 & 0.6554 \\
\hline Number of Short Term Loans & 0.0049 & -0.0107 \\
\hline Number of Medium Term Loans & 0.0058 & $0.0139 * *$ \\
\hline Number of Long Term Loans & 0.0170 & $0.0264 * *$ \\
\hline Sector Share of Firm & 0.0053 & -0.0012 \\
\hline \multicolumn{3}{|l|}{ Market (Non-Risk Lender) Characteristics } \\
\hline Largest Lender Assets/Firm Assets & $0.0068^{* *}$ & 0.0035 \\
\hline Lender Market Concentration & 0.0001 & -0.0031 \\
\hline Proportion of Real Estate Lenders & 0.0008 & -0.0004 \\
\hline Lender Experience & $0.0095^{* *}$ & 0.0027 \\
\hline Largest Lenders Lending Effort & 0.0062 & 0.0027 \\
\hline \multicolumn{3}{|l|}{ Firm Specific Risk Characteristics } \\
\hline Sales Growth Dummy Variables & $* * *$ & @ \\
\hline Too New to Report & 0.0656 & -0.0019 \\
\hline Sales Growth > 5\% & 0.0197 & -0.0313 \\
\hline Sales Growth $<-5 \%$ & $0.0795^{* * *}$ & 0.0134 \\
\hline Business Development Stage Dummy Variables & @ & $*$ \\
\hline Start-Up & 0.0428 & $0.0729 * *$ \\
\hline Expansion & $0.0411^{*}$ & $0.0457 * *$ \\
\hline Owner Transition & 0.0583 & 0.0315 \\
\hline 1986 Debt/1986 Sales & $0.0344 * *$ & -0.0014 \\
\hline 1986 Debt/1986 Assets & 0.0336 & 0.0403 \\
\hline Manger Experience & $-0.0303 * *$ & 0.0064 \\
\hline Firm's Sector Dummy Variables & @ & @ \\
\hline Manufacturing & -0.0384 & -0.0231 \\
\hline Construction & -0.0059 & -0.0347 \\
\hline Other Nonretail & 0.0363 & 0.0147 \\
\hline Tourism & 0.0346 & -0.0237 \\
\hline
\end{tabular}

\footnotetext{
${ }^{* * * *, * * *}$ Original coefficient estimate is significantly different from zero at the $0.10,0.05$, or 0.01 level, respectively.

@ An F test of this class of dummy variables indicated that they were not significant at 0.10 .

- The number of observations is the number of firms responding to the dependent variable and all of the independent variables. It includes all possible responses to the dependent variable.
} 
long-term loans have more difficulty than do corporations and short-term borrowers.

The negative coefficient on medium-term loans confirms the problems firms have acquiring loans with maturities over 12 months. While a bank may regularly roll over shortterm loans, this practice puts a firm's financing at riskrelative to longer term investments. The negative coefficient on sector share of firms is a puzzle because it implies more dominant local sectors acquire a smaller share of debt from banks. If banks are stimulated by portfolio diversification concerns, the coefficient suggests limited use of commonly available diversification mechanisms (e.g., guarantees, correspondents). Yet, the positive lender experience coefficient leads to the conclusion that seeking a bank with more experience with a specific firm type increases those firms' use of bank funds.

Firms with a high debt-to-sales ratio obtain a lower share of their new debt from a commercial bank, indicating that banks limit credit extended to firms with a seemingly insufficient cash flow to repay debt. The insignificant debtto-asset ratio coefficient implies factors other than collateral constrain the use of debt finance from banks. This evidence suggests that bank evaluation of lending risk reflects repayment capacity, rather than only a collateral guarantee.

\section{Share of New Debt Obtained Locally}

After adjusting for risk, a business will raise an 11\% lower share of its new debt locally if it is larger than $\$ 500,000$ in assets, as compared to firms with less than $\$ 100,000$ in assets. If a firm is in an economic sector with which the local lender has expertise, it will raise a higher share of its new debt locally. We conclude that a lack of lender expertise limits the availability of local finance.

Firms using medium-term debt had to rely on nonlocal banks and other capital sources. The significant negative relationship between lending effort and use of local banks could reflect bank response to the minimal use of local banks, rather than causing low local bank use.

Local banks apparently consider business organization structure in their lending decision, but this model does not distinguish how that occurs. Local banks make clear distinctions against tourism related businesses and the other non-retail firms (i.e., services, wholesale, transportation). The reduced use of local banks for financing high debt/asset firms indicates customary bank management practices, but when linked to the negative other non-retail coefficient may imply a reluctance to lend if physical collateral is absent.

\section{Share of New Equity Obtained Locally}

The entire equation for share of new equity obtained locally is not significantat the $10 \%$ level. New equity for very small firms is primarily obtained in the form of retained eamings or personal debt of the business owner. On average, sample firms obtained $90 \%$ of their new equity from these sources. In the case of larger firms, equity is more likely to be obtained in the form of what is traditionally termed external equity financing (i.e., sale of stock or equity positions to outside investors).

The negative coefficient on the start-up businesses can be interpreted in two ways, and other survey evidence supports both interpretations. First, the local equity capital network is not developed and it is therefore difficult for startups to find local "sponsors" for their venture. Only five of the 37 lenders could name a local equity capital "angel." Second, firms are turning to nonlocal (more than 15 miles away) sources for equity funding. This may reflect a relatively large number of the new start-ups, in one of the survey counties, which were started by new residents. The data are unable to distinguish the dominant cause.

\section{Conclusions}

This multivariate analysis of 815 nonfarm businesses in 15 local capital markets in four rural Wisconsin counties suggests that rural capital markets are functioning adequately for most segments of the local nonfarm business sector. Adequacy is definedas equal access to funding after adjusting for risk characteristics of specific businesses. Tests of whether the firms had a loan request denied or underfunded, or the extent firms use bank debt, use local banks, and local equity to finance their operations indicate non-risk factors affect decisions.

After adjusting for risk, firms most likely denied financing include those with assets exceeding $\$ 100,000$; those that are small relative to the largest local lender, and those where the local lender has already made a relatively larger financial commitment to the firm's business. When these firms are dependent on local lenders, capital market adequacy problems exist.

After adjusting for risk, firms with assets over $\$ 500,000$ and with a relatively large number of medium-and long-term loans are more likely to experience an underfunding of a loan request. The positive relationship between number of medium- and long-term loans and probability of underfunding simply indicates that firms using the market more are more likely to experience underfunding. The positive coefficient on start-ups and underfunding but not on denials probably arises from unsuccessful start-ups (denied) exclusion from the analysis. Or perhaps lenders viewed the start-up as risky, but nonetheless chose to make a risky investment in the community, albeit not a 'full' investment.

Generally, lenders discriminate among loan applications according to such standard risk indicators as declining sales, high debt to asset ratios, new management 
Table 2

Sources of New Financing Used By Businesses

\begin{tabular}{lccc}
\hline & $\begin{array}{l}\text { Share of New } \\
\text { Debt from a Bank }\end{array}$ & $\begin{array}{l}\text { Share of New } \\
\text { Debt Raised } \\
\text { Locally }\end{array}$ & $\begin{array}{l}\text { Share of New } \\
\text { Equity Raised } \\
\text { Locally }\end{array}$ \\
\hline $\begin{array}{l}\text { Number of Observations } \\
\text { Mean of Dependent Variable }\end{array}$ & 245 & 237 & 163 \\
Log Likelihood Ratio Chi-Square for equation & 0.66 & 0.84 & 0.86 \\
& $85.75^{* * *}$ & $45.26^{* *}$ & 37.69 \\
& Partial & Partial & Partial \\
& Derivative & Derivative & Derivative
\end{tabular}

Non-Risk Business Characteristics

Business Size Dummy Variables Assets $\$ 100,000-499,000$ Assets $\geq \$ 500,000$

$\stackrel{@}{0.0136}$
-0.0092
0.0206
$*$

Number of Nonlocal Locations

Business Organization Dummy Variables Partnership Corporation Cooperative

Number of Short Term Loans

Number of Medium Term Loans

Number of Long Term Loans

Sector Share of Firm

Market (Non-Risk Lender) Characteristics

Largest Lenders Assets/Firm Assets

Lender Market Concentration

Proportion of Real Estate Lenders

Lender Experience

Largest Lenders Lending Effort

Firm Specific Risk Characteristics

Sales Growth Dummy Variables

Too New To Report

Sales Growth > 5\%

Sales Growth $<-5 \%$

Business Development Stage Dummy Variables

Start-Up

Expansion

Ownership Transition

1986 Debt/1986 Sales

1986 Debt/1986 Assets

Manager Experience

Firm's Sector Dummy Variables

Manufacturing

Construction

Other Nonretail

Tourism

0.1136
$0.4629^{*}$
$0.0987^{*}$
$0.0273^{*}$
$-0.0507^{* * *}$
0.0494
$-0.0133^{* * *}$

$-0.0750$

0.1053

$-0.0007$

$0.0023 * *$

0.0005

$@$
-0.2241
0.0153
0.0212
$@$

$-0.1227$

$-0.0129$

0.0761

$-0.0596^{* *}$

0.0427

0.0211

@

$-0.0254$

1.2001

$-0.0557$

$-0.0910$

$* * *$
$-0.0535^{*}$
$-0.1094^{* * *}$
-0.0059
$*$
0.1116
0.5351
-0.0059
0.0062
$-0.0104 * *$
0.0095
-0.0024

$-0.0494$

$-0.0539$

0.0004

$0.0010^{* *}$

-0.0150 *

@

$-0.1094$

$-0.0056$

$-0.0733$

$-0.2371$

$-0.1903$

$-0.0223$

0.0001

$-0.0328$

0.0594

0.0033

$-0.0695$

0.4495

$-0.0020$

$-0.0003$

0.0519

$@$
-0.0274
-0.0145
0.0013

$-0.0624$

$-0.0183$

0.0680

0.0037

$-0.0637^{*}$

0.0039

0.0398

0.5560

$-0.0618^{*}$

$-0.0868^{* *}$
@

0.2054

0.0782

0.0882

$-0.3069 *$

$-0.1257$

0.0854

$-0.0103$

0.0593

$-0.0720$

$0.3384^{*}$

1.4476

$-0.0958$

$-0.2675^{*}$

\footnotetext{
${ }^{*},{ }^{* *},{ }^{* * *}$ Original coefficient estimate is significantly different from zero at the $0.10,0.05$, or 0.01 level, respectively.

@ An F test of this class of dummy variables indicated that they were not significant at 0.10 . The number of observations is the number of firms responding to the dependent variable and all of the independent variables. It includes all possible responses to the dependent variable.
} 
(ownership transition) and start-up and expansion stage businesses. Increased management experience reduces the prospects of denial.

Local debt markets are less able to respond to the needs of larger firms (i.e., total assets exceeding $\$ 500,000$ ), but a local lender's increased experience with a particular sector facilitates the use of local debt capital. It appears that lender knowledge of a firm's business sector increases the firm's chance of acquiring a loan up to the point where the lender's commitment to the sector reaches a certain level and portfolio diversification becomes an issue. Local lenders may not be exploiting existing portfolio and risk diversification mechanisms.

The use of bank debt is related to the number of shortterm loans held by the firm. This suggests that nonfarm businesses seeking short-term debt are probably able, after risk adjustment, to acquire such financing through local banks. However, the use of medium- and long-term debt from local sources is more problematic.

\section{Policy Implications}

The fact that rural capital markets do not function adequately for nonfarm businesses does not in itself justify public intervention. Capital may have more productive uses in other markets. The government may desire to intervene in the market economy for reasons of efficiency or equity. The policy implications which follow assume that the public wishes to increase the availability of capital to rural areas, for whatever reason.

From this analysis we see that existing rural capital markets are providing adequate funding for most nonfarm businesses. Businesses on the margins of size, types of industry, stage of development and rates of growth have the greatest difficulty in acquiring adequate capital. The primary problem appears to be one of an inadequate flow of information to borrowers, lenders, and policymakers regarding business plan development, alternative funding sources, loan evaluations and mechanisms for distributing risk.

Community education and technical assistance are mechanisms for increasing information flow in rural capital markets. Programs aimed at assisting small and start-up firms in improving the quality of their business plans and debt and equity requests might improve loan request acceptance rates. Information exchanges linking businesses of all sizes with contacts outside of their community might increase access to alternative sources of capital.

Lenders in more isolated rural areas might be provided technical assistance in evaluating unique loan applications. Regardless of the quality of any loan application, it may be necessary for the capital provider to disperse the risk. There is evidence of widespread reluctance to use available mechanisms (i.e., loan guarantees, secondary markets, loan participation). Additional incentives or procedural modifications which encourage greater risk dispersal might be established.

If improving the flow of information regarding capital distribution proves ineffective, perhaps other more direct initiatives might be tried. Options could include using regulatory authority to direct more capital to rural areas, providing capital directly to individual businesses through government loans or venture capital pools, establishing target areas for interest subsidization, and expanding government guarantees focused on rural areas.

\section{References}

Barkley, David L. and Paul E. Helander. "Commercial Bank Loans and Nonmetropolitan Economic Activity: A Question of Causality." The Review of Regional Studies. 15:1 (1985). 26-32.

Boggs, Bruce S., David J. Sorenson and Andrew M. Isserman. Commercial Lending Patterns and Economic Development In West Virginia. Berea, KY: Mountain Association for Community Economic Development, Inc., 1988.

Council of Northeast Economic Action. An Empirical Analysis of Unmet Demand in Domestic Capital Markets in Five U.S. Region. Boston, MA: Research Division, Council of Northeast Economic Action, 1981.

Garvin, W.J. "The Small Business Financing Gap: The Special Case of Minority Enterprise." Journal of Finance. 26 (May, 1971). 445-457.

George, Edwin B. and Robert J. Landry. "The Federal Reserve Board Report on Small Business Financing." Journal of Business. 32 (July, 1959). 212-228.

Ho, Yan Ki. "Commercial Banking and Regional Growth: The Wisconsin Case." Unpublished Ph.D. Dissertation. Madison, WI: Department of Agricultural Economics, University of Wisconsin. 1979.

Horvitz, Paul H. and R. Richardson Pettit (eds.). Small Business Finance: Sources of Financing for Small Business. Greenwich, CT: JAI Press, 1984.

Mikesell, James and Steve Davidson. "Financing Rural America: A Public Policy and Research Prospective." Rural Financial Markets: Research Issues for the 1980s. Chicago, IL: Federal Reserve Bank of Chicago, 1982. 159-197.

Pulver, Glen and Ron Hustedde. "Regional Variables Which Influence The Allocation of Venture Capital: The Role of Banks." Review of Regional Studies. 18:2 (1988). 1-9.

Rogers, Glen, Ron Shaffer and Glen Pulver. "Identification of Local Capital Markets for Policy Research." Review of Regional Studies. 18:1 (1988). 55-66.

Shaffer, Ron E. and Glen C. Pulver. "Regional Variations in the 
Capital Structure of New Small Businesses: The Wisconsin Case." In D.J. Storey (ed.). Small Firms in Regional Economic Development. Cambridge, England: Cambridge University Press, 1985. 166-192.

, Glen C. Pulver, Glenn Rogers, Tim Wojan and Dan Gerland. Rural Nonfarm Businesses' Access to Debt and Equity Capital. Madison, WI: Department of Agricultural Economics, University of Wisconsin, 1989.

Sorenson, David J. and Andrew M. Isserman. "Rural Urban
Differences in Bank Lending Levels: The Importance of Management and Other Factors." Paper presented at 27th Annual Meeting Southem Regional Science Association, Morgantown, WV (1988).

Taff, Steven J., Glen C. Pulver and Sydney D. Staniforth. “Are Small Community Banks Prepared to Make Complex Business Loans." Research Report 3263. Madison, WI: College of Agriculture and Life Sciences, University of WisconsinMadison, 1984. 